\title{
A Rare Case of Arteriovenous Malformation of Mandible: A Case Report
}

\author{
Vandita Chaurasia ${ }^{1}$, Ruchika Tiwari $^{2}$, Vikas Singh $^{3}$, Prateek Agarwal ${ }^{4}$, Gaurang Thanvi ${ }^{5}$
}

\begin{abstract}
Arteriovenous malformation (AVM) is a congenital disorder of the veins and arteries that makeup the vascular system. This report presents a case of AVM in the body and ramus region of left side of mandible in a 22-year-old male. The case presents with diffuse swelling present on left region of the body and ramus area of mandible since 8 months. Malformation was diagnosed with the help of detailed patient history, clinical evaluation, radiographs, and computed tomography (CT) scans. The definitive diagnosis was made by CT angiography. Later hemimandibulectomy with simultaneous reconstruction by a titanium plate was done.

Keywords: Arteriovenous malformation, Hemimandibulectomy, Mandible, Stereolithographic model.

Journal of Mahatma Gandhi University of Medical Sciences \& Technology (2019): 10.5005/jp-journals-10057-0100
\end{abstract}

\section{INTRODUCTION}

An abnormal connection between arteries and veins is termed as arteriovenous malformation and is usually present at birth. Vascular anomalies can be further subdivided into vascular hemangiomas, arteriovenous, capillary, and lymphatic malformations. Arteriovenous malformations (AVMs) are usually congenital, and there are known genetic mutations that can lead to an increased occurrence throughout the body. Symptoms of AVM vary according to the location of the malformation. Roughly $88 \%$ are asymptomatic, and surgical treatment is necessary in symptomatic AVMs. Current treatment of AVM mandible involves surgical resection of mandible in conjunction with embolization to help control hemorrhage. The recommended treatment is radical resection of the affected part of the jaw. Vascular anomalies often affect the soft tissues of maxillofacial region because of their ability to cause significant hemorrhage, and intraosseous venous anomalies can be lifethreatening entities. Spontaneous hemorrhage is reported to cause 25 deaths. $^{1-4}$

\section{Case Description}

A 22-year-old male presents with diffuse swelling, since 8 months, extending anteriorly from the left corner of the mouth to posteriorly $2 \mathrm{~mm}$ anterior to left tragus. Superiorly, the swelling extends from upper molar region to $1 \mathrm{~cm}$ below lower border of mandible. There was marked facial Asymmetry with fullness over left side of the face. The lesion was asymptomatic and nonpulsatile. On intraoral examination, the whole dentition was intact with all sets of permanent teeth, there was obliteration of gingiva buccal complex of left posterior mandibular area (Fig. 1).

\section{Radiographic and Computed Tomography Findings}

An orthopantomograph of mandible denotes a radiolucent lesion that has well-defined borders, which extends from the root of permanent mandibular second molar of the left side involving mandibular third molar of left side to the ramus of mandible. Threedimensional (3D) computed tomography (CT) of the face revealed
${ }^{1-5}$ Department of Oral and Maxillofacial Surgery, Mahatma Gandhi Dental College and Hospital, Mahatma Gandhi University of Medical Sciences and Technology, Jaipur, Rajasthan, India

Corresponding Author: Vandita Chaurasia, Department of Oral and Maxillofacial Surgery, Mahatma Gandhi Dental College and Hospital, Mahatma Gandhi University of Medical Sciences and Technology, Jaipur, Rajasthan, India, Phone: +916378446534, e-mail: vandychaurasia@gmail.com

How to cite this article: Chaurasia V, Tiwari R, Singh V, et al. A Rare Case of Arteriovenous Malformation of Mandible: A Case Report. J Mahatma Gandhi Univ Med Sci Tech 2019;4(1):14-17.

Source of support: Nil

Conflict of interest: None

expansion of body and ramus area of the left side of mandible extending till left condyle of mandible (Fig. 2).

\section{Biopsy}

Fine-needle aspiration cytology (FNAC) was done with 22-bore needle, and it revealed fresh blood on aspiration which believed that the lesion might be AVM. CT angiography was done and highlighted AVM of the left mandible (Fig. 3).

\section{Operative Procedure}

Following all hematological examinations, the patient was planned for surgery under general anesthesia. Extended submandibular incision was given. Selective dissection was done from medial to lateral side to approach the lesion. Facial artery, masseteric artery, inferior alveolar artery, and mental artery ligation was done prior to resection, and medial pterygoid muscle was dissected and stripped. Mandible was resected from distal to the lower canine on left side till the condyle. Hemorrhage was controlled by using electrocautery and bone wax. Reconstruction of the jaw was done with a titanium reconstruction plate with condylar head preadapted on stereolithographic model using 3D CT scan. Gross appearance of mass was smooth, nodular, capsulated which measured $7.5 \times 7.5 \times$ $4 \mathrm{~cm}$. Histopathological section confirmed it as an AVM (Figs 4 to 7).

(c) The Author(s). 2019 Open Access This article is distributed under the terms of the Creative Commons Attribution 4.0 International License (https://creativecommons. org/licenses/by-nc/4.0/), which permits unrestricted use, distribution, and non-commercial reproduction in any medium, provided you give appropriate credit to the original author(s) and the source, provide a link to the Creative Commons license, and indicate if changes were made. The Creative Commons Public Domain Dedication waiver (http://creativecommons.org/publicdomain/zero/1.0/) applies to the data made available in this article, unless otherwise stated. 

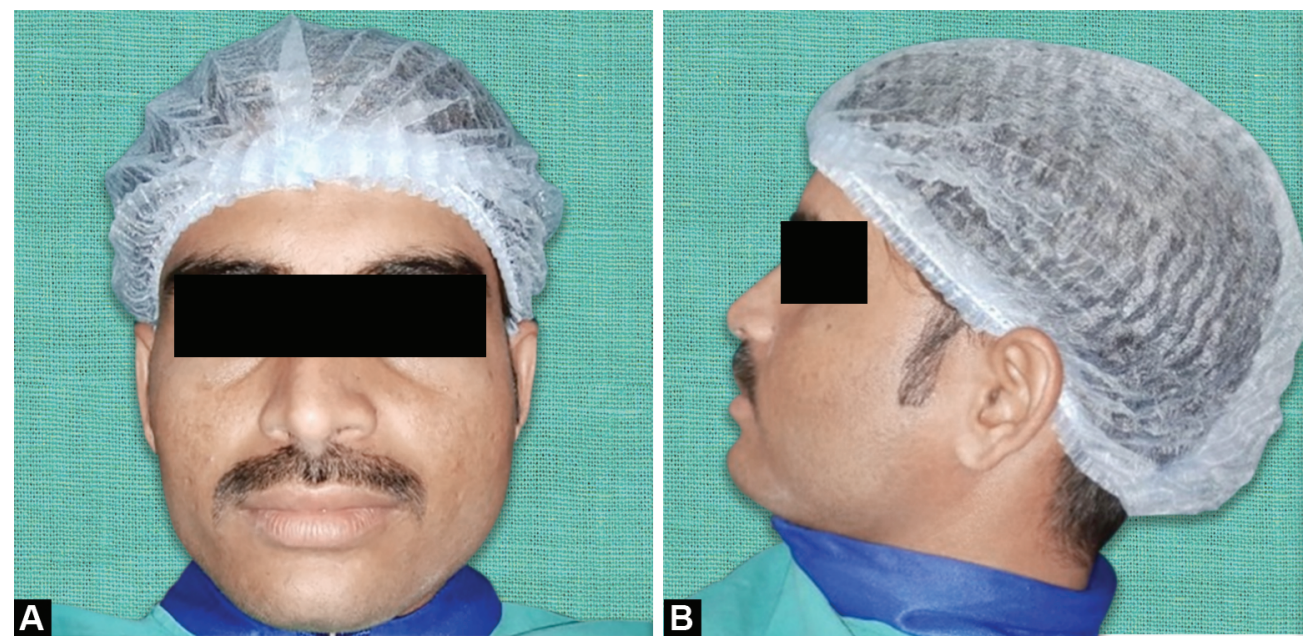

Figs $1 \mathrm{~A}$ and B: Preoperative picture
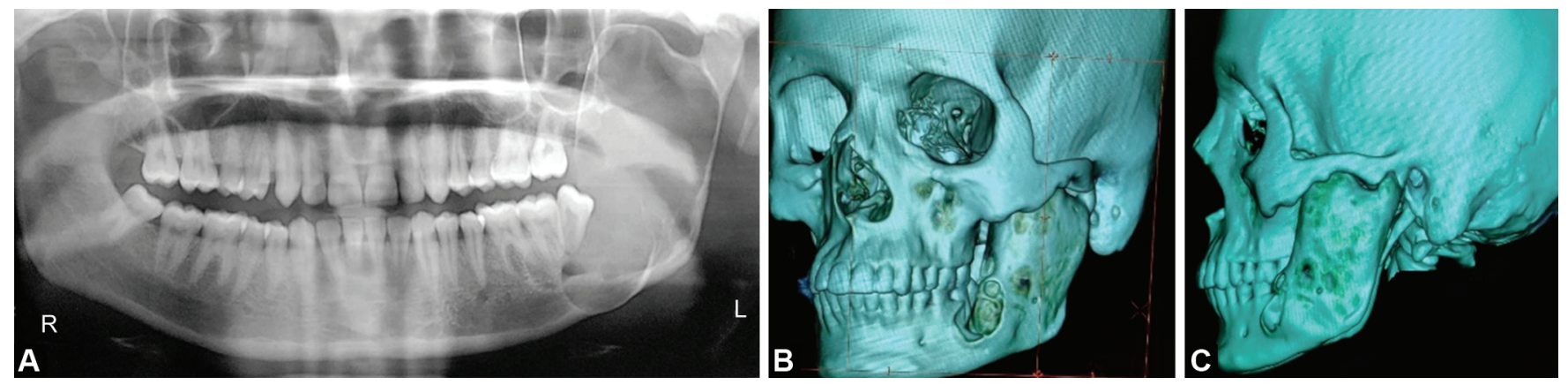

Figs $2 \mathrm{~A}$ to $\mathrm{C}$ : An orthopantomograph and three-dimensional reconstruction scans showing the lesion
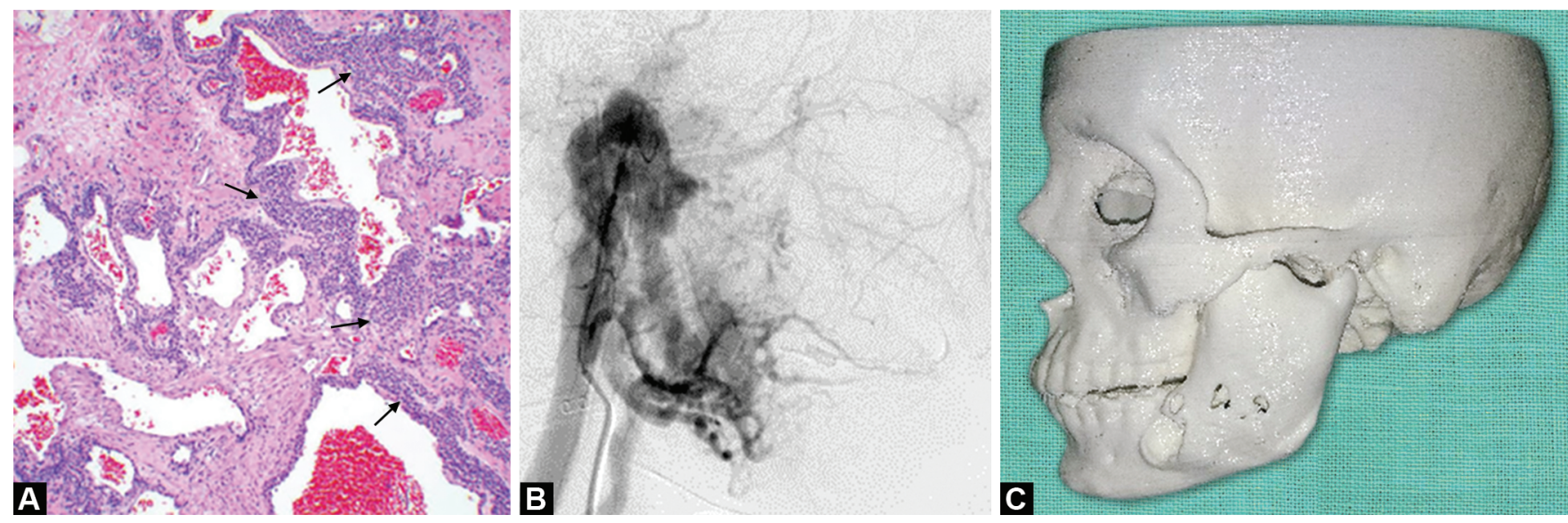

Figs 3A to C: Histopathological section of arteriovenous malformation (AVM), angiography of arteriovenous malformation (AVM) and stereolithographic model

\section{Discussion}

Arteriovenous malformation of the mandible is a rare entity but has significant potential for mortality due to massive hemorrhage. These vascular anomalies are widely known because of its occurrence in the central venous system but can appear in any location. They can cause intense pain, swelling, and bleeding which leads to serious medical problems. AVMs appear radiographically like other lesions in the bone, and most radiolucent lesions should be aspirated before biopsy is performed to prevent major complications. ${ }^{5}$ On aspiration, we obtain bright red blood in syringe 
if AVM is suspected. ${ }^{6} \mathrm{CT}$ angiography is confirmatory diagnosis for AVM. Surgery is the most common treatment for AVM. In some cases, a catheter or radiation may be used to close off blood vessels.

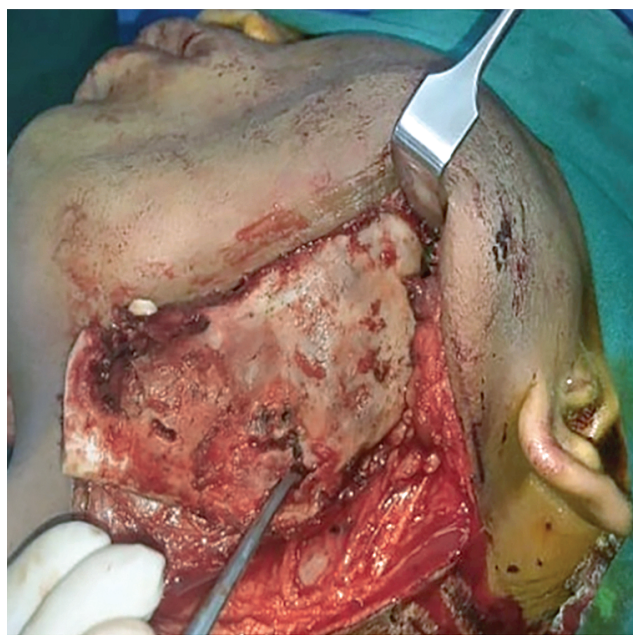

Fig. 4: Extended submandibular incision

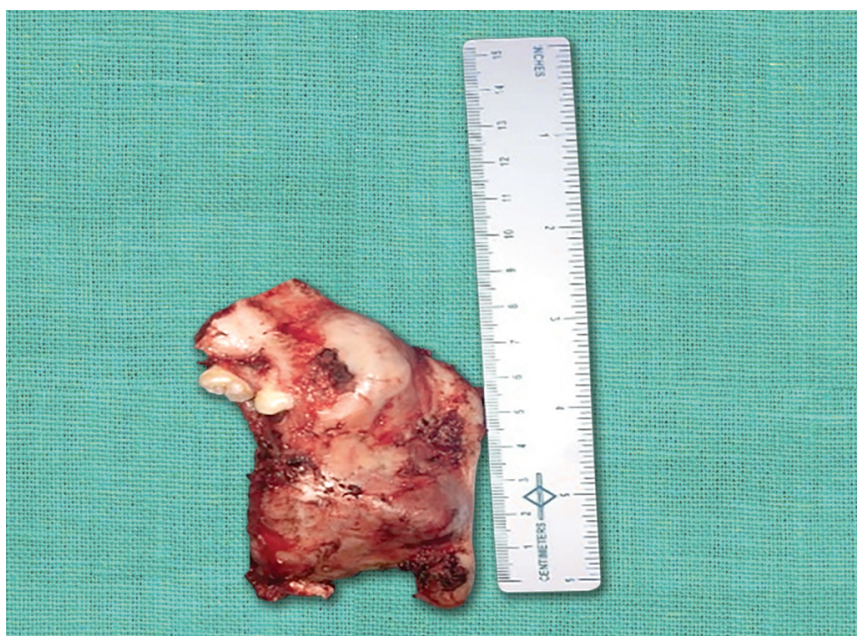

Fig. 5: Gross appearance of excised mass
Medications may be used to treat particular symptoms if present. In some cases, ligation of external carotid artery is done where bleeding cannot be controlled. To diagnose the AVM, we need to look for symptoms and perform a physical examination to listen for sounds caused by varied rapid flow of blood through the arteries and veins of an AVM. ${ }^{7}$ Cryosurgery, radiation, and sclerosing agents have also been used as treatment for AVM. ${ }^{8}$ Surgery along with vessel embolization has been indicated as a definitive treatment (Table 1). ${ }^{9}$

\section{Conclusion}

Arteriovenous malformations present as an asymptomatic swelling that gradually increases over time. Due to its asymptomatic nature, a careful approach toward a definite diagnosis should be made by excluding other lesions. Microscopic examination along with CT angiography is the gold standard for making a definite diagnosis. ${ }^{10-12}$ Treatment planning should be cautiously done based upon patients clinical features, physical examination, CT findings, extension of the lesion clinically, and radiographically and comorbid condition. Angiography confirmed the diagnosis further to which treatment plan was made that involved ligation of the vessels and resection of involved region of mandible, which further achieved

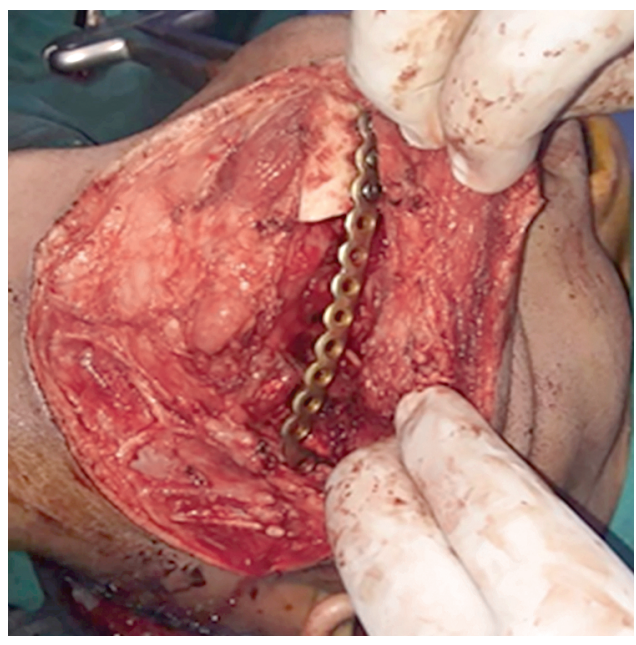

Fig. 6: Reconstruction done using recon plate
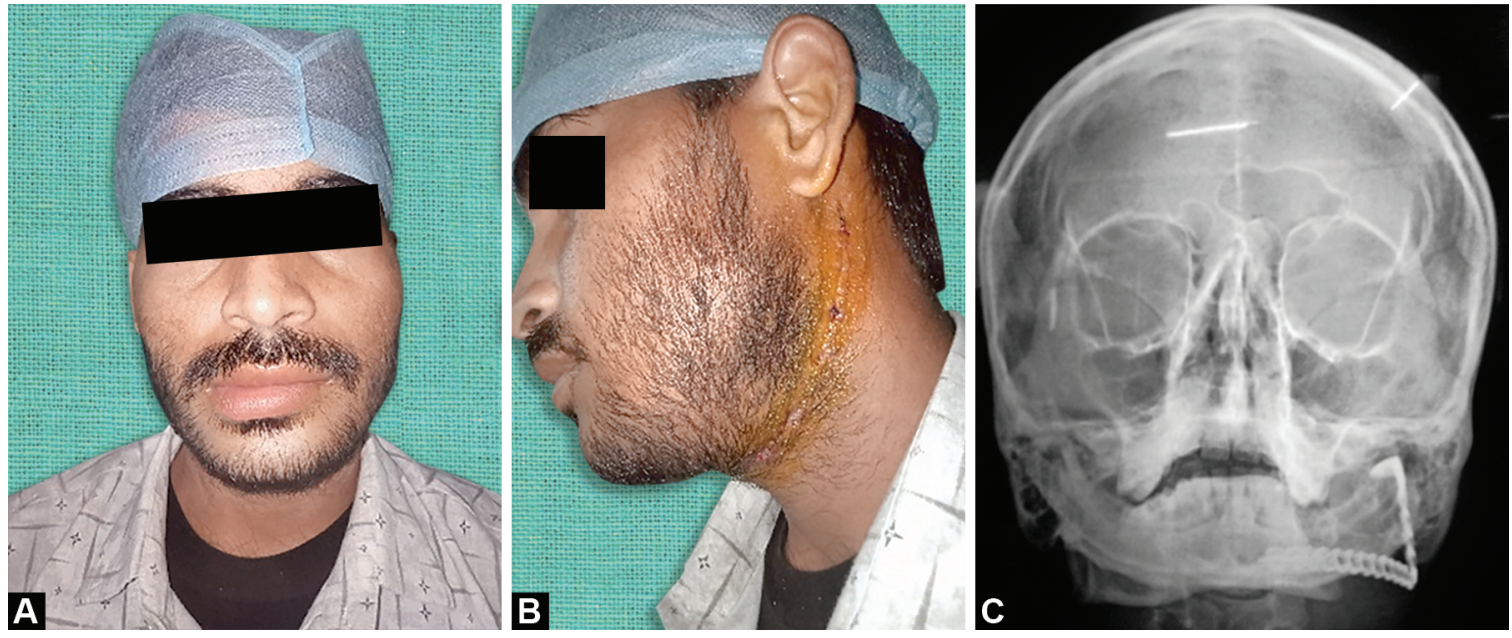

Figs 7A to C: (A and B) Postoperative pictures; (C) X-ray of the paranasal sinus 
Table 1: Updated ISSVA classification of vascular anomalies

\begin{tabular}{|c|c|}
\hline Vascular tumors & Vascular malformations \\
\hline $\begin{array}{l}\text { - Infantile hemangiomas } \\
\text { - Congenital hemangiomas (rich and nich) } \\
\text { - Tufted angioma (with or without Kasabach-Merritt } \\
\text { syndrome) } \\
\text { - Kaposiform hemangioendothelioma (with or without } \\
\text { Kasabach-Merritt syndrome) } \\
\text { - Spindle cell hemangioendothelioma } \\
\text { - Other rare hemangioendotheliomas (epithelloid, } \\
\text { composite, retiform, polymorphous, dabska tumor, } \\
\text { lymphangioend } \\
\text { otheliomatosis, etc.) } \\
\text { - Dermatologic acquired vascular tumors (pyogenic } \\
\text { granuloma, targetoid hemangioma, glumeruloid } \\
\text { hemangioma, microvenular hemangioma, etc.) }\end{array}$ & 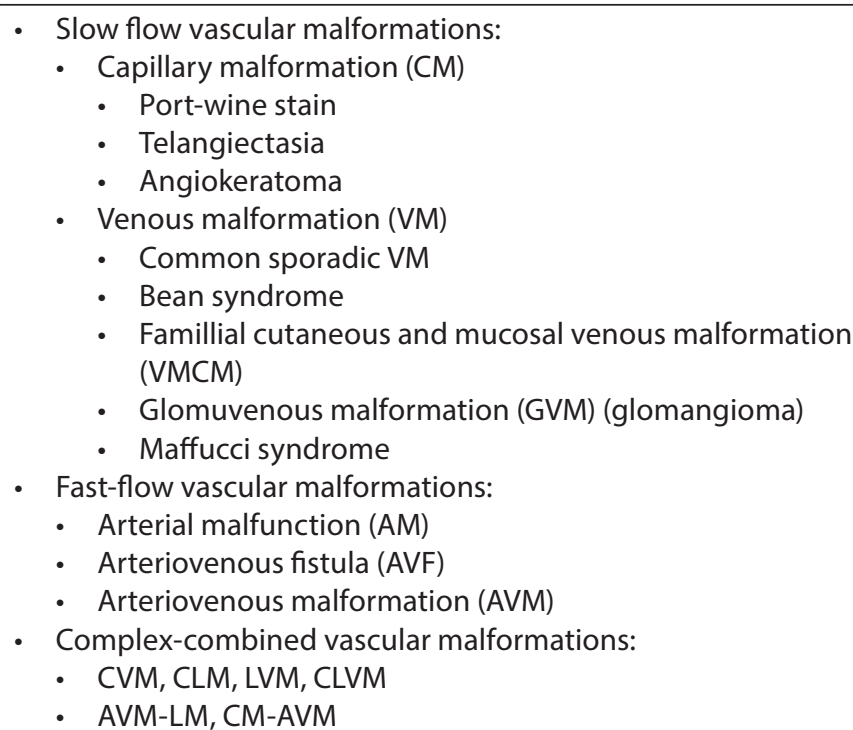 \\
\hline
\end{tabular}

C, capillary; $\mathrm{V}$, venous; L, lymphatic; $\mathrm{AV}$, arteriovenous; $\mathrm{M}$, malformation; $\mathrm{RICH}$, rapidly involuting congenital hemangioma; $\mathrm{NICH}$, noninvoluting congenital hemangioma

Ref: International Society for Study of Vascular Anomalies ${ }^{13}$

good results in the case. The patient had no signs of recurrence in 8 months of follow-up after surgery.

\section{References}

1. Adler CP, World L. Haemangioma and related lesions Fletcher CD, Unni KK, Mertens F, ed. Pathology and Genetics of Tumours of Soft Tissue and Bone. World Health Organisation Classification of Tumours. Lyon, France: IARC Press; 2002. p. 320.

2. Dahlin DC, Unni KK. Bone Tumors: General Aspects and Data on 8542 Cases. Springfield IL: Charles C Thomas; 1996.

3. Lamberg MA, Tasanen A, Jaaskelainen J. Fatality from central hemangioma of the mandible. J Oral Surg 1979;37(8):578.

4. Fathi M, Manafi A, Ghenaati $H$, et al. Large arteriovenous high flow mandibular malformation with exsanguinating dental socket hemorrhage: a case report. J Craniomaxillofac Surg 1997;25(4):228. DOI: 10.1016/s1010-5182(97)80080-7.

5. Kaban LB, Mulliken JB. Vascular anomalies of the maxillofacial region. J Oral Maxillofac Surg 1986;44(3):203-213. DOI: 10.1016/02782391(86)90109-6.

6. Mulliken JB, Glowacki J. Hemangiomas and vascular malformations ininfants and children: a classification based on endothelial characteristics. Plast Reconstr Surg 1982;69(3):412-422. DOI: 10.1097/00006534-198203000-00002.

7. Hall EH. What you don't see can hurt you. N Y State Dent J 1993;59(3):45-47.

8. Gallagher DM, Hilley D, Epker BN. Surgical treatment of an arteriovenous malformation of the mandible in a child. J Maxillofac Surg 1983;11(6):279-283. DOI: 10.1016/s0301-0503(83)80066-6.

9. Babin RW, Osbon DB, Khamgure MS. Arteriovenous malformation of the mandible. Otolaryngol Head Neck Surg 1983;91(4):366-371. DOI: 10.1177/019459988309100404.

10. Mohammadi H, Said-al-Naief NA, Heffez LB. Arteriovenous malformation of the mandible: report of a case with a note on the differential diagnosis. OralSurg Oral Med Oral Pathol Oral Radiol Endod 1997;84(3):286-289. DOI: 10.1016/S1079-2104(97) 90344-9.

11. Bouloux GF, Perciaccante VJ. Massive hemorrhage during oral andmaxillofacial surgery: ligation of the external carotid artery or embolization? J Oral Maxillofac Surg 2009;67(7):1547-1551. DOI: 10.1016/j.joms.2009.03.014.

12. Anderson JA, Grisius RJ, McKean TW. Arteriovenous malformation of the mandible. Oral Surg Oral Med Oralpathol 1981;52(2):118-125. DOI: 10.1016/0030-4220(81)90306-6.

13. International Society for the Study of Vascular Anomalies. 